\title{
Treatment of Focal Articular Cartilage Defects in the Knee
}

\author{
A Systematic Review
}

\author{
Robert A. Magnussen MD, Warren R. Dunn MD, MPH, \\ James L. Carey MD, Kurt P. Spindler MD
}

Received: 26 June 2007 / Accepted: 12 December 2007/Published online: 12 January 2008

(C) The Association of Bone and Joint Surgeons 2008

\begin{abstract}
We asked whether autologous chondrocyte implantation or osteochondral autograft transfer yields better clinical outcomes compared with one another or with traditional abrasive techniques for treatment of isolated articular cartilage defects and whether lesion size influences this clinical outcome. We performed a literature search and identified five randomized, controlled trials and one prospective comparative trial evaluating these treatment techniques in 421 patients. The operative procedures included autologous chondrocyte implantation, osteochondral autograft transfer, matrix-induced autologous chondrocyte implantation, and microfracture. Minimum followup was 1 year (mean, 1.7 years; range, 1-3 years). All studies documented greater than $95 \%$ followup for clinical outcome measures. No technique consistently had superior results compared with the others. Outcomes for microfracture tended to be worse in larger lesions. All studies reported improvement in clinical outcome measures in all treatment groups when compared with preoperative assessment; however, no control (nonoperative) groups were used in any of the studies. A large prospective trial investigating these techniques with the addition of a control group would be the best way to definitively address the clinical questions.
\end{abstract}

One or more of the authors has received funding from the Vanderbilt Sports Medicine research fund (RAM, WRD, JLC, KPS), the National Institute of Arthritis and Musculoskeletal and Skin Diseases (NIH Grant 5K23 AR052392-02) (WRD), and the Pfizer Scholars Award in Clinical Epidemiology (WRD).

R. A. Magnussen, W. R. Dunn, J. L. Carey, K. P. Spindler ( $\square)$ Vanderbilt Orthopaedic Institute, 4200 Medical Center East, 1215 21st Avenue South, Suite 4200, Nashville, TN 37232-8774, USA

e-mail: kurt.spindler@vanderbilt.edu
Level of Evidence: Level II, therapeutic study. See the Guidelines for Authors for a complete description of levels of evidence.

\section{Introduction}

Full-thickness articular cartilage defects have limited regenerative potential. These defects can cause knee discomfort and swelling and eventually may contribute to premature development of osteoarthritis [9]. In a report on 31,516 arthroscopies, these lesions occurred in a minimum of one of every 100 knee arthroscopies [13]. An ideal treatment for these lesions would result in regeneration of the hyaline cartilage in the area of the defect that is integrated with surrounding normal cartilage and mechanically functional.

Multiple techniques have been developed during the past several decades to address this difficult problem. Subchondral drilling [38], abrasion [28], and microfracture [44] have been reported as methods for stimulation of articular cartilage healing. These methods all involve breaching the subchondral bone to allow pluripotent stem cells from the marrow to remodel the fibrin clot in the defect into fibrocartilage. More recently, methods not so dependent on recruitment of pluripotent cells have been proposed. Osteochondral autograft transfer (OAT) has been developed to replace articular cartilage defects with osteochondral autografts [3, 22]. This technique involves harvesting one large graft or multiple smaller cylinders (mosaicplasty) from minimal weightbearing portions of the distal femur and transplanting them to cover defects in higher weightbearing areas. Autologous chondrocyte implantation (ACI) involves placement of cultured chondrocytes in the articular cartilage defect $[5,20]$. The 
original method relied on a sutured periosteal cover (ACI-P) to keep the chondrocytes in the desired location and porcine-derived collagen covers (ACI-C) were developed later. More recently, suture-free biodegradable scaffolds have been used in matrix-induced autologous chondrocyte implantation (MACI) [10].

The surgeon considering treatments of these articular defects thus is faced with multiple options. Review of the literature yields numerous retrospective case series of results of abrasive techniques [28, 38, 42-44], OAT $[3,18,21,26]$, and ACI $[4-7,15,32,33,36,37,39]$. These case series are Level IV data without comparison groups, many of which are written by the originators of the surgical technique being described. A recent review by Jakobsen et al. [27] identified 61 publications on cartilage repair, varying from prospective, randomized studies to case series, and noted their generally low methodologic quality.

We therefore embarked on a systematic review of the best evidence in the literature to answer the following clinical questions: (1) does one advanced cartilage repair technique such as ACI or OAT yield better clinical outcomes than another or show superior outcomes to traditional abrasive techniques for treatment of isolated Outerbridge Stage 3 or 4 articular cartilage defects?; and (2) does lesion size influence clinical outcome to a greater extent in one technique than in others?

\section{Materials and Methods}

To address the clinical questions outlined, we elected to perform a systematic review of Levels I and II studies. We did not require use of any one specific clinical outcome measure for inclusion as substantial diversity in clinical outcome measures was anticipated. If sufficient studies comparing similar groups, interventions, and outcome measures were identified, a meta-analysis was planned. If the resulting data were too heterogeneous for meta-analysis, clinical results would be summarized and expressed in tables for review by readers.

We performed a literature search of MEDLINE, the Cochrane Central Register of Controlled Trials, EMBASE, and the Cumulative Index for Nursing and Allied Health Literature (CINAHL) to identify all prospective comparative studies evaluating operative treatment of articular cartilage defects of the knee with ACI or OAT. The MEDLINE search of articles published between January 1, 1966, and January 1, 2007, yielded 11,885 papers containing any one of the follow terms: autologous chondrocyte, ACI, osteochondral, OATS, mosaicplasty, microfracture, abrasion, or chondroplasty. These studies were narrowed to 1092 by requiring that they also contain the term knee. The search then was limited to English articles on human subjects classified by MEDLINE as randomized, controlled trials, clinical trials, controlled clinical trials, or multicenter studies. We then reviewed the abstracts of the resulting 37 studies.

Publications were included in this review if they were prospective comparative studies comparing results of treatment of full-thickness (Outerbridge Grade 3 or 4) lesions. The modified Outerbridge classification was defined as follows: Grade 0, normal cartilage; Grade 1, cartilage softening and swelling; Grade 2, fissures not reaching subchondral bone; Grade 3, fissures to subchondral bone; and Grade 4, exposed subchondral bone [34, 35]. Studies were required to include at least 30 patients, have at least 1 year of followup, and compare either ACI or OAT with another treatment method. We identified and included five randomized, controlled trials [1, 2, 19, 29, 45] and one prospective comparative trial [24] in the previously cited literature review. All references in these articles were reviewed manually in search of other possible studies and none was identified.

Twenty-nine studies were excluded from the analysis because they were not related to articular cartilage repair (18 papers) or they were not trials comparing two or more repair techniques (11 studies). Two additional studies were excluded because one had too few subjects and less than 1 year of followup [14] and the other was a trial comparing two different techniques of ACI [16].

A search of the Cochrane Central Register of Controlled Trials was done using the same search strategy yielding 23 studies, including the six trials identified previously. No other studies meeting inclusion and exclusion criteria were identified. A search of EMBASE using these criteria yielded 335 studies including the six trials identified previously. The remaining studies did not meet criteria. Use of the same search on CINAHL yielded 133 studies. The three randomized, controlled trials identified already were included in the previously mentioned study and the remaining 130 did not meet criteria.

A templated evidence-based medicine literature review form was used to assist in the systematic review of articles and the data were collected [17, 30, 41]. Demographic data presented for comparison include publication date, author, journal, surgical procedures evaluated, total number of subjects, mean patient age, method of randomization, percent traumatic lesions, interval from injury to surgery, and lesion size and location (Table 1). Additional study details, including mean followup, details of followup evaluations, the presence of cointerventions, and rehabilitation protocol were noted (Table 2). Primary and secondary clinical outcomes, results of arthroscopic and histologic evaluations, and the use of independent observers also were recorded (Table 3). 


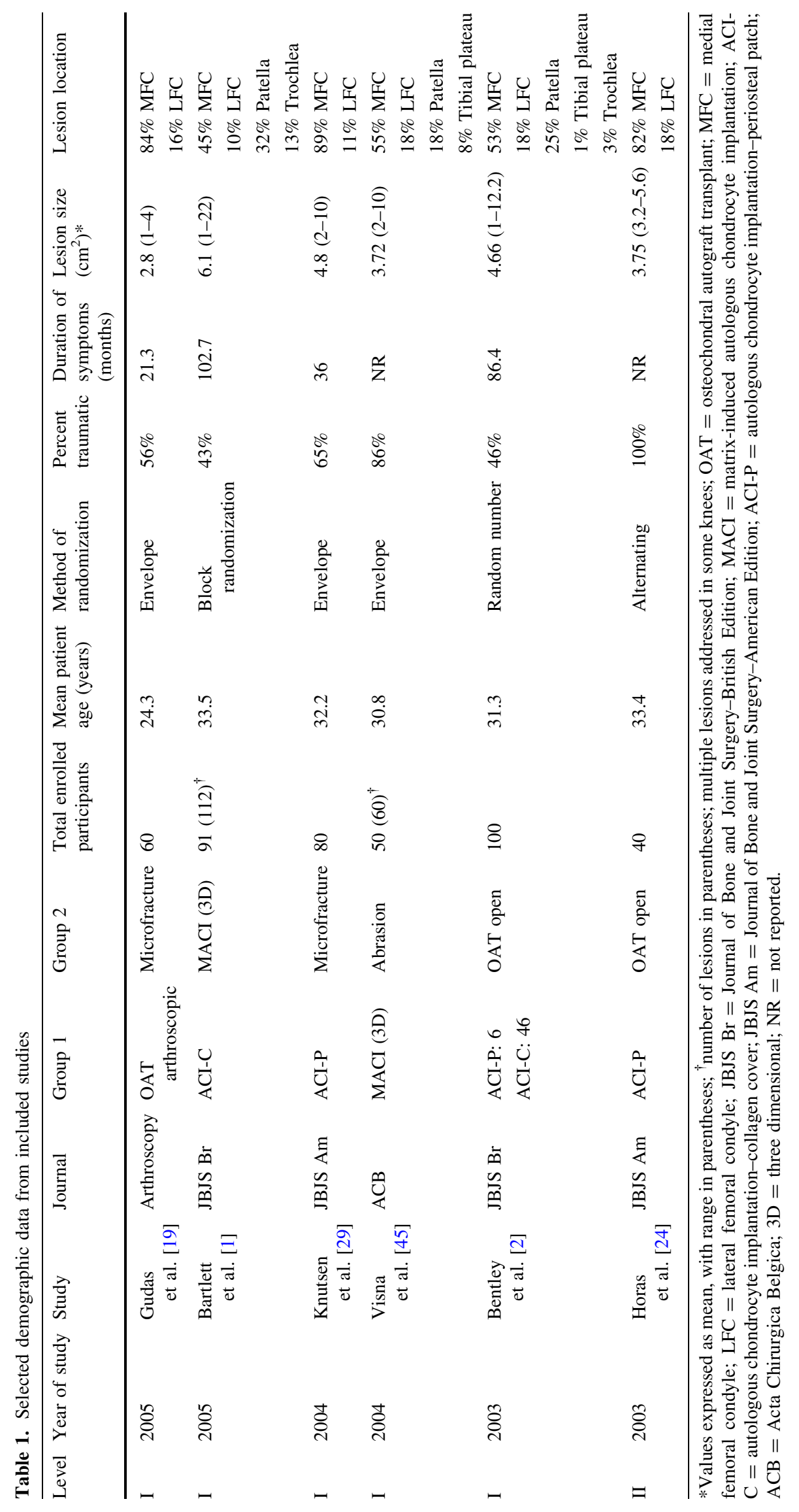


Table 2. Followup

\begin{tabular}{|c|c|c|c|c|c|c|c|c|}
\hline Study & $\begin{array}{l}\text { Followup (years) } \\
\text { for primary } \\
\text { clinical outcome }\end{array}$ & $\begin{array}{l}\text { Participants } \\
\text { evaluated } \\
\text { clinically }\end{array}$ & $\begin{array}{l}\text { Participants } \\
\text { evaluated } \\
\text { arthroscopically }\end{array}$ & $\begin{array}{l}\text { Participants } \\
\text { evaluated } \\
\text { histologically }\end{array}$ & Cointerventions & CPM & $\begin{array}{l}\text { Time to } \\
\text { partial } \\
\text { weightbearing }\end{array}$ & $\begin{array}{l}\text { Time to full } \\
\text { weightbearing }\end{array}$ \\
\hline Gudas et al. [19] & 3 & $57(95 \%)$ & $34(57 \%)^{*}$ & $25(42 \%)^{*}$ & None & No & 4 weeks & 8 weeks \\
\hline Bartlett et al. [1] & 1 & $91(100 \%)$ & $42(46 \%)$ & $25(27 \%)$ & None & No & 1 day & 10 days \\
\hline Knutsen et al. [29] & 2 & $80(100 \%)$ & $77(96 \%)$ & $67(84 \%)$ & None & Yes & 1 day & $8-12$ weeks \\
\hline Visna et al. [45] & 1 & $50(100 \%)$ & $4(8 \%)^{\dagger}$ & $4(8 \%)^{\dagger}$ & $\begin{array}{l}22 \text { (MACI group) } \\
19 \text { (abrasion group) }\end{array}$ & NR & 3 weeks & $6-8$ weeks \\
\hline Bentley et al. [2] & 1 & $100(100 \%)$ & $60(60 \%)^{*}$ & $19(19 \%)^{\S}$ & NR & No & NA & 1 day \\
\hline Horas et al. [24] & 2 & $40(100 \%)$ & $12(30 \%)^{*}$ & $11(28 \%)^{*}$ & None & Yes & 2 weeks & 12 weeks \\
\hline
\end{tabular}

*Nonrandom selection of patients to evaluate arthroscopically and biopsy; ${ }^{\dagger}$ all from MACI group; ${ }^{*} 64 \%$ of patients with ACI and $55 \%$ of patients with OAT; ${ }^{\S}$ all from ACI groups; $\mathrm{CPM}=$ continuous passive motion; $\mathrm{NR}=$ not reported; NA $=$ not applicable; MACI $=$ matrix-induced autologous chondrocyte implantation; $\mathrm{ACI}=$ autologous chondrocyte implantation; OAT $=$ osteochondral autograft transplant.

Details of the study design used by the authors to control major confounding variables and possible biases were recorded and evaluated on a published evidence-based medicine form [41]. Each was assigned a level of evidence according to published guidelines of the Journal of Bone and Joint Surgery [47] and a modified Coleman Methodology Score [11] (Table 1). The modified Coleman Methodology Score is an attempt to quantify the overall quality of study design and execution, including sample size, length of followup, blinding, adequacy of description of procedures and rehabilitation protocol, and other study characteristics [11, 12].

All six studies required the patients to have isolated Outerbridge Stage 3 or 4 lesions without generalized osteoarthritis, although two studies did include patients in whom multiple lesions were addressed [1, 45]. The majority of lesions were on the femoral condyles, although several studies included lesions in other regions of the knee $[1,2,45]$. All authors required a stable knee except for Visna et al. [45], whose patients had concurrent anterior cruciate ligament reconstruction and were included in both groups (seven of 25 patients in the MACI group and three of 25 in the abrasion group). Lesion size and duration of symptoms varied considerably among the studies but were equal between treatment groups in all six studies. All studies focused on patients between skeletal maturity and an upper age limit between 40 and 50 years. The study by Gudas et al. [19] was unique because they included only patients who were competitive or well-trained athletes by International Cartilage Repair Society criteria, whereas others included patients regardless of activity level [8]. Trauma was the most common etiology of the lesions in all studies. Gender, age, body mass index, and lesion location and etiology were equal between treatment groups in all studies reviewed.

Two studies used the microfracture technique as described by Steadman et al. [42-44] without substantial modifications [19, 29]. Arthroscopic awls were used to make multiple 2-mm holes 3 to $4 \mathrm{~mm}$ apart in the affected region.

Visna et al. [45] used the abrasion technique as described by Johnson [28]. Abrasion was completed to 1 to $2 \mathrm{~mm}$ using the arthroscopic shaver.

Osteochondral autograft transfer was performed in three studies by press-fitting osteochondral plugs from the margins of the trochlea into débrided cartilage defects. Bentley et al. [2] attempted to leave the transplanted cartilage slightly proud to ensure contact with the tibia, whereas the other groups attempted to align the grafts with the surrounding cartilage surface. Bentley et al. [2] and Gudas et al. [19] used osteochondral plugs of one fixed diameter, whereas Horas et al. [24] used multiple sizes. Gudas et al. [19] included only all-arthroscopic procedures, whereas Bentley et al. [2] and Horas et al. [24] performed the procedure through a medial or lateral arthrotomy.

Autologous chondrocyte implantation was performed in four studies using relatively similar methods (Table 4) $[1,2,24,29]$. Matrix-induced autologous chondrocyte implantation was performed in two studies [1, 45]. Both groups used Tissucol ${ }^{\circledR}$ (Baxter AG, Vienna, Austria) as the matrix and implanted between five and 10 million cells 3 to 5 weeks after harvest.

Among the six studies, the minimum followup was 1 year (mean, 1.7 years; range, 1-3 years). All had greater than $95 \%$ followup for clinical outcome measures, whereas only Knutsen et al. [29] were able to obtain greater than $80 \%$ followup for arthroscopic and histologic evaluations. Rehabilitation protocols generally were similar, although time to partial and full weightbearing varied among studies (Table 2). All authors used identical rehabilitation protocols of both treatment groups in their studies.

Multiple clinical scoring systems were used to quantify clinical outcomes. International Cartilage Repair Society cartilage repair assessment scores were used to quantify 


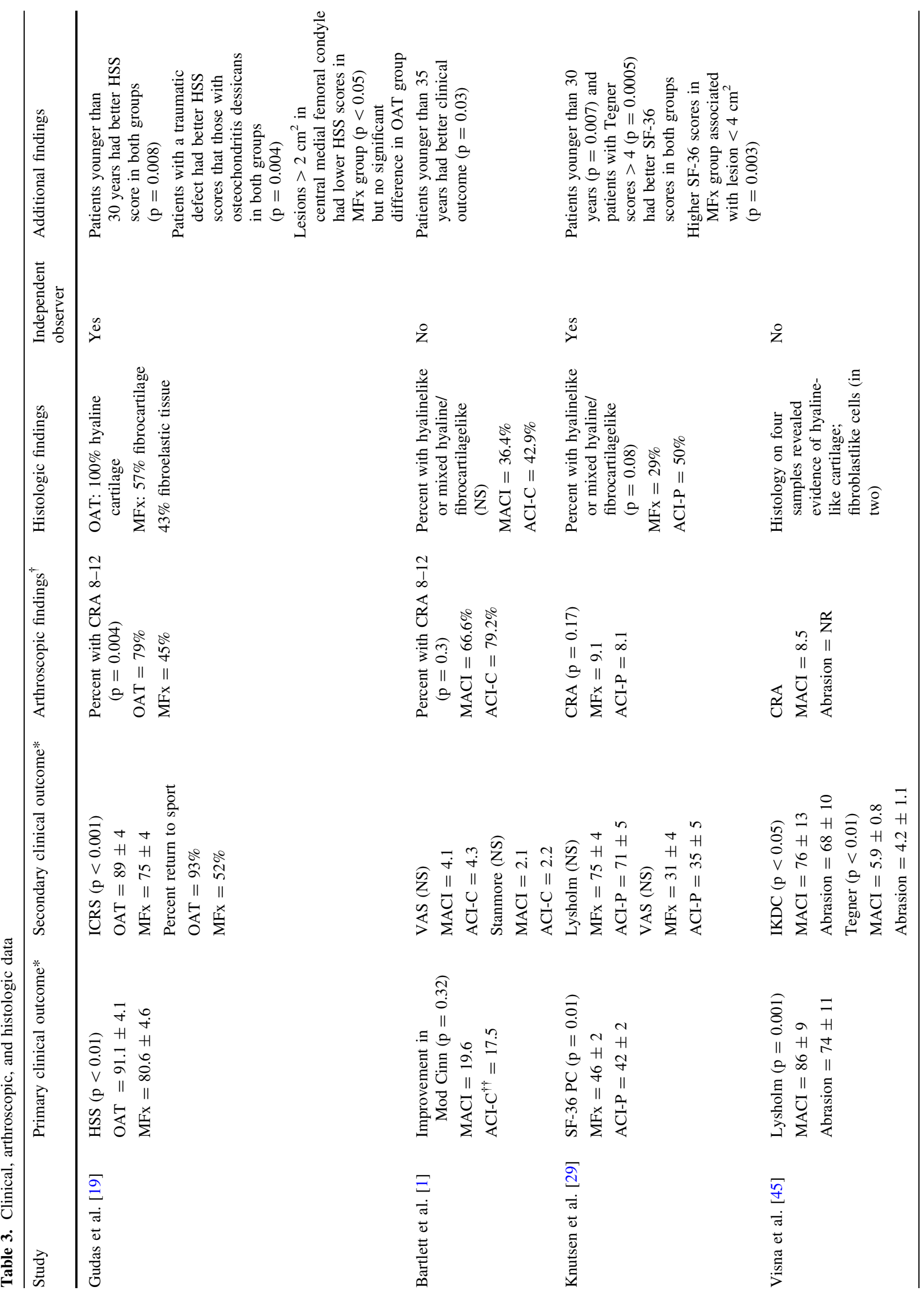




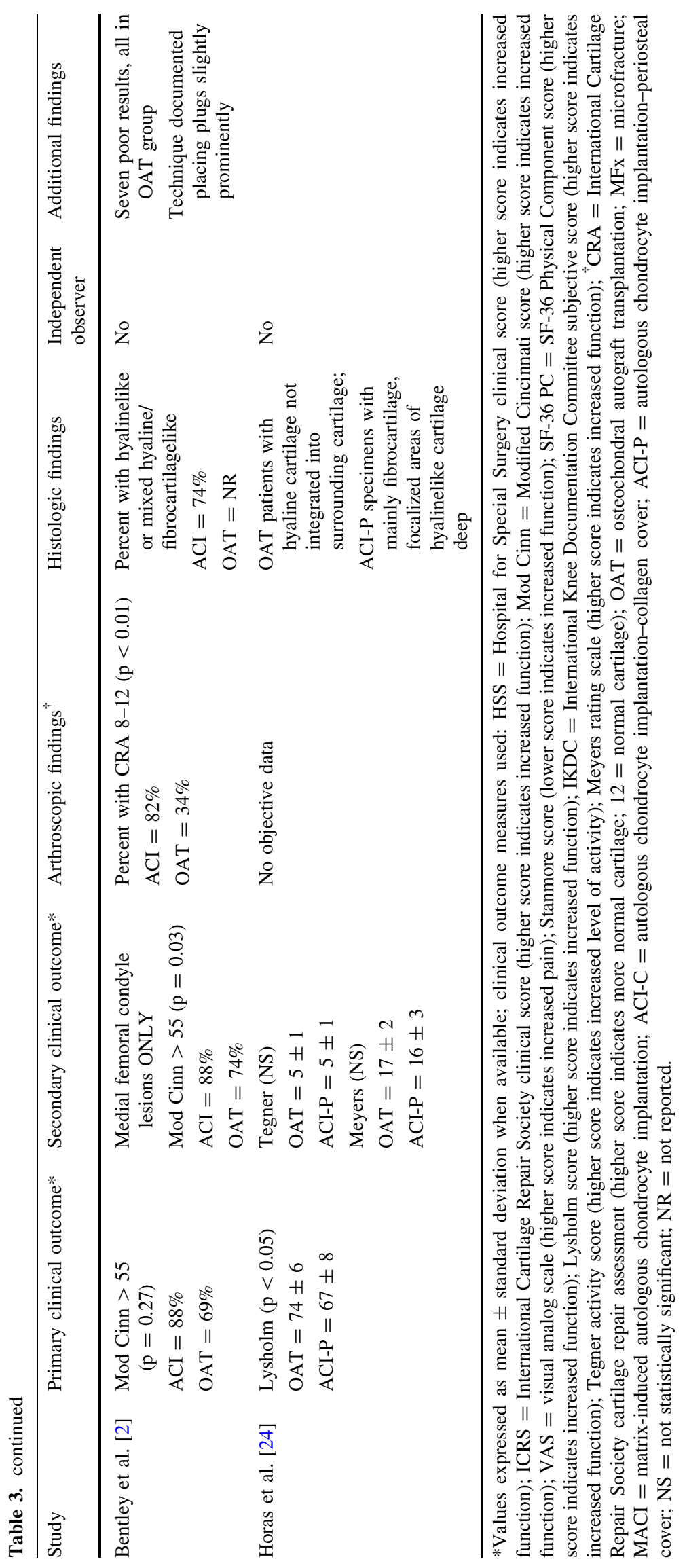


Table 4. Autologous chondrocyte implantation technique

\begin{tabular}{|c|c|c|c|c|c|c|}
\hline Study & Donor site & $\begin{array}{l}\text { Culture } \\
\text { laboratory }\end{array}$ & $\begin{array}{l}\text { Incubation } \\
\text { time (weeks) }\end{array}$ & $\begin{array}{l}\text { Number of } \\
\text { cells implanted }\end{array}$ & Cover & $\begin{array}{l}\text { Method of cover } \\
\text { attachment }\end{array}$ \\
\hline Bartlett et al. [1] & Trochlear margins & $\begin{array}{l}\text { Verigen (Leverkusen, } \\
\text { Germany) }\end{array}$ & $3-5$ & NR & Collagen & Suture and fibrin glue \\
\hline Knutsen et al. [29] & $\begin{array}{l}\text { Proximal medial } \\
\text { femoral condyle }\end{array}$ & $\begin{array}{l}\text { Genzyme (Cambridge, } \\
\text { MA) }\end{array}$ & 4 & NR & Periosteum & Suture and fibrin glue \\
\hline Bentley et al. [2] & Trochlear margins & In house & $3-5$ & $5-10 \times 10^{6}$ & Collagen/periosteum & Suture and fibrin glue \\
\hline Horas et al. [24] & $\begin{array}{l}\text { Proximal medial } \\
\text { femoral condyle }\end{array}$ & In house & $2-3$ & $3-6 \times 10^{6}$ & Periosteum & Suture \\
\hline
\end{tabular}

$\mathrm{NR}=$ not reported

arthroscopic findings in five of the six studies. Four studies attempted to quantify the percentage of hyaline cartilage seen histologically (Table 3).

Selection bias in each study was influenced by patient inclusion criteria and method of randomization to groups. All studies had clear inclusion criteria that were similar and all but Horas et al. [24] used a random method of patient allocation. However, in four studies, there was selection bias in choosing which patients underwent arthroscopic and histologic evaluation that was influenced by factors including patient consent or the occurrence of a subsequent injury, or a choice was made to focus these evaluations on one treatment group only or specific patients in each group.

Performance bias was carefully limited in all studies. Lesion size and location, patient age, and rehabilitation protocol were similar between treatment groups in each study.

Only the study by Visna et al. [45] included patients who underwent cointerventions at the same time as the index procedure and these patients were distributed equally between the two groups.

Transfer bias was minimized in all studies regarding clinical followup, with each group attaining at least $95 \%$ followup. However, only Knutsen et al. [29] attained greater than $80 \%$ followup for the arthroscopic and histologic evaluations. Accepted followup has been defined as $70 \%$ of the study population, although greater than $80 \%$ of the study population is preferred [17, 46, 47].

Detection bias was minimized by Gudas et al. [19] and Knutsen et al. [29] by using independent observers to evaluate outcomes; however, the other four studies do not have this independent observation. Validated patient-oriented outcome measures such as the SF-36 [46] or the International Knee Documentation Committee [23] rating scale were not used by Bartlett et al. [1], Bentley et al. [2], and Horas et al. [24].

As described, all six studies included in this review were subject to some degree of bias. The modified Coleman Methodology Score [11] is an attempt to quantify the degree to which possible bias is controlled. The highest score (least bias) was noted in the study by Knutsen et al. [29]. The nonrandomized study by Horas et al. [24] yielded the lowest score (Table 1).

\section{Results}

Comparing OAT with microfracture, Gudas et al. [19] reported the OAT group had better $(\mathrm{p}<0.01)$ clinical scores, more normal-appearing $(\mathrm{p}=0.004)$ cartilage on visual assessment, and a subjectively greater percentage of hyaline cartilage histologically. Bartlett et al. [1] found no clinical, arthroscopic, or histologic differences between MACI and ACI-C. In comparing microfracture with ACI-P, Knutsen et al. [29] noted better ( $p<0.01$ ) SF-36 scores in the microfracture group but no difference in other clinical measures or arthroscopic or histologic analyses. Visna et al. [45] compared MACI with abrasion and reported improved $(\mathrm{p}<0.001)$ clinical scores with MACI. Bentley et al. [2] and Horas et al. [24] compared OAT with ACI. Bentley et al. [2] noted more normal $(p<0.01)$ cartilage on arthroscopic examination in the ACI group, whereas Horas et al. [24] reported an improved $(p<0.05)$ clinical score with OAT.

Three of the six studies reviewed included analysis of influence of lesion size on outcome [1, 19, 29]. Gudas et al. [19] reported clinical outcomes of microfracture were worse in lesions larger than $2 \mathrm{~cm}^{2}(\mathrm{p}<0.05)$. They observed no association between clinical outcomes and lesion size when patients were treated with OAT. Knutsen et al. [29], however, reported worse clinical outcomes in lesions greater than $4 \mathrm{~cm}^{2}$ when treated with microfracture $(\mathrm{p}<0.003)$ but noted no association between clinical outcome and size after ACI. Bartlett et al. [1] reported no dependence of clinical outcome on lesion size for lesions treated with ACI or MACI.

The five studies that reported preoperative clinical scores found improvement in clinical outcome measures in all treatment groups at the end of the study when compared with preoperatively (Table 3 ). Combining the patients in 


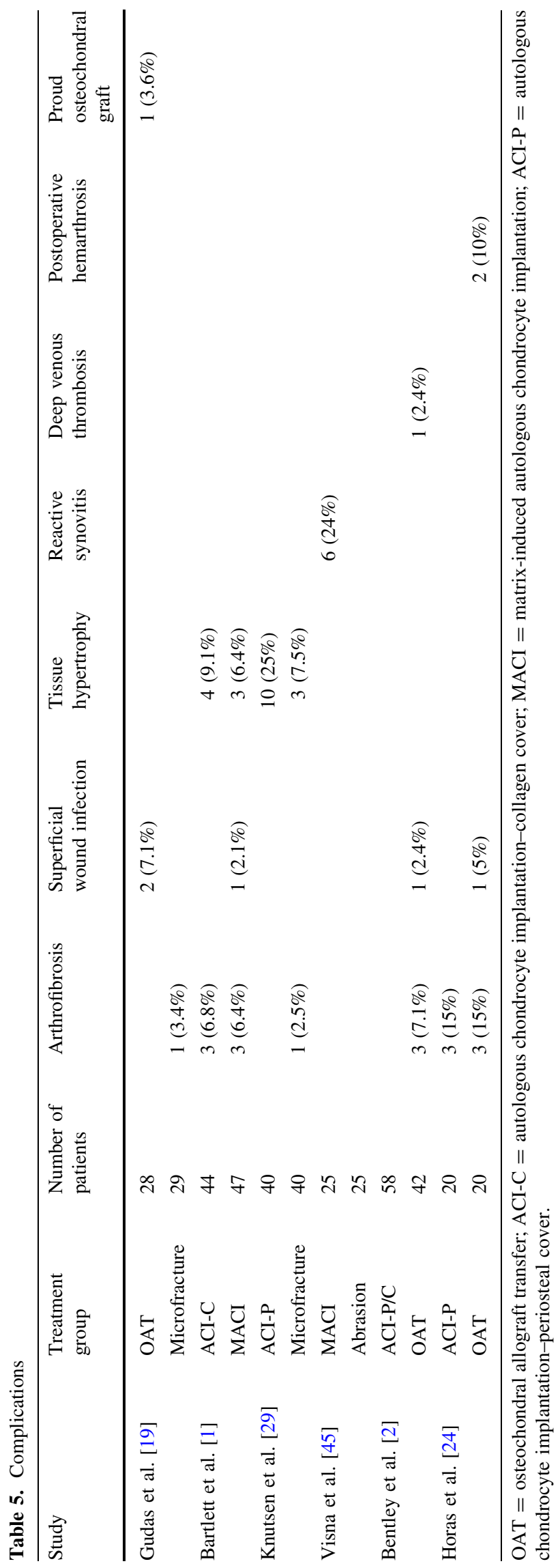

both treatment arms, Gudas et al. [19] reported the Hospital for Special Surgery score improved $(\mathrm{p}<0.05)$ from a mean of 77 preoperatively to 86 at 1 year and improvement $(\mathrm{p}<0.05)$ in International Cartilage Repair Society score improved from 51 to 82 during the same period. Similarly, Bartlett et al. [1] reported a 19-point improvement $(\mathrm{p}<0.01)$ in the mean Cincinnati knee score at 1 year. Knutsen et al. [29] noted an improvement $(\mathrm{p}<0.0001)$ in visual analog pain score from 55 to 33 2 years after surgery and increases $(p=0.003)$ in Lysholm knee score from 56 to 73 and SF-36 physical component scores from 39 to 44. Visna et al. [45] described an improvement in Lysholm score from 50 to 80, increase in International Knee Documentation Committee score from 43 to 72 , and improvement in Tegner activity score from 2.7 to $5.1(\mathrm{p}<0.01)$. Horas et al. [24] noted increases in Lysholm score from 27 to 70 over 2 years, improvement in Meyers score from 8 to 17 , and increase in Tegner activity score from 2 to 5 during the same period. Bentley et al. [2] did not provide preoperative clinical scores.

All six studies reported complications (Table 5). Common complications encountered in the reviewed papers included arthrofibrosis, superficial wound infections, and tissue hypertrophy. Much lower incidences of deep venous thrombosis, hemarthrosis, and graft malpositioning were reported. Arthrofibrosis appeared with equal frequency in all treatment groups. Superficial wound infection, deep venous thrombosis, and hemarthrosis appeared most commonly with OAT. Tissue hypertrophy surrounding the lesion and reactive synovitis were associated more commonly with MACI and ACI. Proud or recessed graft placement is by definition limited to the OAT procedure. In the study by Knutsen et al. [29], the reoperation rate in the ACI group was $25 \%$ (10 of 40 ), whereas it was $10 \%$ (four of 40) in the microfracture group.

\section{Discussion}

The past 20 years have seen evidence-based medicine play an increasingly important role in physicians' decision making as they determine optimal treatments for their patients. In an evidence-based medicine hierarchy, controlled trials, specifically randomized, controlled trials and controlled, prospective cohort studies, should be weighted most highly in clinical decision making [17, 25, 30, 47]. We have presented data from six Levels I and II studies providing the best data currently available to assess clinical outcomes of advanced cartilage repair techniques relative to each other and to abrasive techniques.

Substantial limitations in the available literature on treatment of full-thickness cartilage defects are apparent in this review. Although data from all of these trials reveal 
considerable short-term improvement in all clinical scores with every treatment method evaluated, the lack of a placebo group in these trials limits interpretation of these data to comparisons between treatment methods. The natural history of these defects has been reported in several series, but we were unable to identify any trials comparing operative treatment of the defects with nonoperative management or with simple débridement. One long-term study of 28 minimally treated cartilage defects consisting of $89 \%$ partial-thickness defects and $11 \%$ full-thickness defects showed fair to poor knee function in $25 \%$ at 14 years [31]. Another study of 101 patients with fullthickness defects noted only slightly lower subjective clinical scores and no greater incidence of osteoarthritis at 6 to 9 years when compared with control subjects without cartilage injury [40]. Longer-term followup in the studies included here would allow some comparison to these studies and other historical controls of nonoperative treatment of these defects but still would fall short of a randomized, controlled trial in comparing outcomes. The relatively short followup of all studies identified in this review severely limits interpretation of the data. Any differences in outcome based on the formation of articular rather than fibrocartilage in the defect may be quite subtle and only reveal themselves after many years of followup. Similarly, complications such as donor site morbidity in OAT may be late in their presentation and thus not be detected at short followup. The relatively small number of trials available at the time of this review and the heterogeneity of outcome measures preclude performance of a meta-analysis of the data.

As a result of the above-described limitations in the current literature, we are unable to make a recommendation regarding one superior procedure for all clinical situations. Articular cartilage defects frequently are discovered at arthroscopy and may not be anticipated before the procedure. This situation requires the arthroscopist to make an intraoperative decision regarding the treatment used. The current literature suggests use of any of the treatment methods outlined here results in improved clinical outcome in patients with symptoms, although it is unclear whether this outcome differs from the natural history of these lesions. Microfracture or drilling techniques require little preoperative planning and minimal equipment, and their performance does not preclude performance of OAT or ACI later should symptoms continue. Even in the case of poor patient compliance with postoperative weightbearing limitations, there is a low chance for patient injury. Low morbidity and cost make these techniques ideal first-line treatments for small Stages 3 and 4 articular cartilage defects discovered at arthroscopy. Whether an articular cartilage biopsy for future potential autologous chondrocyte procedure should be obtained depends on several factors, including cost, long-term data, and estimated percentage that would require a second procedure for failed microfracture.

The factors influencing treatment choice for known articular cartilage defects differ in important ways. The disadvantages of OAT and ACI alluded to above, including equipment availability and consent issues, do not apply in this situation. The poorer outcomes of microfracture noted with lesions larger than 2 to $4 \mathrm{~cm}^{2}$ in two studies may reflect the need for more complex surgery for larger lesions. Specific trials aimed and powered to detect outcome difference between lesion sizes are required to attain a definitive answer. Lesion size and location, expected future activity level, surgeon training and comfort level with specific techniques, and patient preference after informed consent are among the most likely factors considered by surgeons in this decision.

The best way to address the question regarding which treatment method is superior would be a large multicenter trial comparing all four techniques described, simple débridement, and a nonoperative control. This trial should use validated patient-oriented clinical outcome measures, such as the Knee Injury and Osteoarthritis Outcome Score, the WOMAC ${ }^{\mathrm{TM}}$ Osteoarthritis Index, SF-36 score, or the International Knee Documentation Committee score, and be continued to obtain longer followup at 5 and eventually 10 years. Until data of this caliber are available, surgeons should base their decision making on their training and experience with different treatment methods, cost-benefit analyses, and patient preference with informed consent regarding the available outcomes data.

Our review of the best available evidence reveals no one technique produces superior clinical results for treatment of full-thickness articular cartilage defects. Microfracture techniques require little preoperative planning and special equipment and failure does not preclude later treatment with ACI or OAT. These factors may influence some surgeons to use microfracture as first-line treatment for articular cartilage defects discovered at arthroscopy. Treatment choice in known lesions requires surgeon interpretation of available data as presented here in light of patient characteristics, lesion location and size, and individual expertise.

Acknowledgments We thank Lynn Cain for editorial assistance and Tara Holmes for assistance in the literature search.

\section{References}

1. Bartlett W, Skinner JA, Gooding CR, Carrington RW, Flanagan AM, Briggs TW, Bentley G. Autologous chondrocyte implantation versus matrix-induced autologous chondrocyte implantation for osteochondral defects of the knee: a prospective, randomised study. J Bone Joint Surg Br. 2005;87:640-645. 
2. Bentley G, Biant LC, Carrington RW, Akmal M, Goldberg A, Williams AM, Skinner JA, Pringle J. A prospective, randomised comparison of autologous chondrocyte implantation versus mosaicplasty for osteochondral defects in the knee. J Bone Joint Surg Br. 2003;85:223-230.

3. Bobic V. Arthroscopic osteochondral autograft transplantation in anterior cruciate ligament reconstruction: a preliminary clinical study. Knee Surg Sports Traumatol Arthrosc. 1996;3:262-264.

4. Brittberg M. Autologous chondrocyte transplantation. Clin Orthop Relat Res. 1999;367(suppl):S147-S155.

5. Brittberg M, Lindahl A, Nilsson A, Ohlsson C, Isaksson O, Peterson L. Treatment of deep cartilage defects in the knee with autologous chondrocyte implantation. N Engl J Med. 1994;331: 889-895.

6. Brittberg M, Peterson L, Sjögren-Jansson E, Tallheden T, Lindahl A. Articular cartilage engineering with autologous chondrocyte transplantation: a review of recent developments. J Bone Joint Surg Am. 2003;85(suppl 3):109-115.

7. Brittberg M, Tallheden T, Sjögren-Jansson E, Lindahl A, Peterson L. Autologous chondrocytes used for articular cartilage repair: an update. Clin Orthop Relat Res. 2001;391(suppl):S337-S348.

8. Brittberg M, Winalski CS. Evaluation of cartilage injuries and repair. J Bone Joint Surg Am. 2003;85(suppl 2):58-69.

9. Buckwalter JA, Mankin HJ. Articular cartilage: degeneration and osteoarthritis, repair, regeneration, and transplantation. Instr Course Lect. 1998;47:487-504.

10. Cherubino P, Grassi FA, Bulgheroni P, Ronga M. Autologous chondrocyte implantation using a bilayer collagen membrane: a preliminary report. J Orthop Surg (Hong Kong). 2003;11:10-15.

11. Coleman BD, Khan KM, Maffulli N, Cook JL, Wark JD. Studies of surgical outcome after patellar tendinopathy: clinical significance of methodological deficiencies and guidelines for future studies. Victorial Institute of Sport Tendon Study Group. Scand J Med Sci Sports. 2000;10:2-11.

12. Cowan J, Lozano-Calderón S, Ring D. Quality of prospective controlled randomized trials: analysis of trials of treatment for lateral epicondylitis as an example. J Bone Joint Surg Am. 2007;89:1693-1699.

13. Curl WW, Krome J, Gordon ES, Rushing J, Smith BP, Poehling GG. Cartilage injuries: a review of 31,516 knee arthroscopies. Arthroscopy. 1997;13:456-460.

14. Dozin B, Malpeli M, Cancedda R, Bruzzi P, Calcagno S, Molfetta L, Priano F, Kon E, Marcacci M. Comparative evaluation of autologous chondrocyte implantation and mosaicplasty: a multicentered randomized clinical trial. Clin J Sports Med. 2005;15:220-226.

15. Gillogly SD, Voight M, Blackburn T. Treatment of articular cartilage defects of the knee with autologous chondrocyte implantation. J Orthop Sports Phys Ther. 1998;28:241-251.

16. Gooding CR, Bartlett W, Bentley G, Skinner JA, Carrington RW, Flanagan A. A prospective, randomised study comparing two techniques of autologous chondrocyte implantation for osteochondral defects in the knee: periosteum covered versus type I/III collagen covered. Knee. 2006;13:203-210.

17. Greenhalgh T. How to Read a Paper: The Basics of Evidence Based Medicine. 2nd ed. London, UK: BMJ Publishing Group; 2001.

18. Gross AE. Repair of cartilage defects in the knee. J Knee Surg. 2002;15:167-169

19. Gudas R, Kalesinskas RJ, Kimtys V, Stankevicius E, Toliusis V, Bernotavicius G, Smailys A. A prospective randomized clinical study of mosaic osteochondral autologous transplant versus microfracture for the treatment of osteochondral defects in the knee joint in young athletes. Arthroscopy. 2005;21:1066-1075.

20. Haddo O, Mahroof S, Higgs D, David L, Pringle J, Bayliss M, Cannon SR, Briggs TW. The use of chondrogide membrane in autologous chondrocyte implantation. Knee. 2004;11:51-55.
21. Hangody L, Feczkó P, Bartha L, Bodó G, Kish G. Mosaicplasty for the treatment of articular defects of the knee and ankle. Clin Orthop Relat Res. 2001;391(suppl):S328-S336.

22. Hangody L, Kish G, Kárpáti Z, Udvarhelyi I, Szigeti I, Bély M. Mosaicplasty for the treatment of articular cartilage defects: application in clinical practice. Orthopedics. 1998;21:751-756.

23. Hefti F, Müller W, Jakob RP, Stäubli HU. Evaluation of knee ligament injuries with the IKDC form. Knee Surg Sports Traumatol Arthrosc. 1993;1:226-234.

24. Horas U, Pelinkovic D, Herr G, Aigner T, Schnettler R. Autologous chondrocyte implantation and osteochondral cylinder transplantation in cartilage repair of the knee joint: a prospective, comparative trial. J Bone Joint Surg Am. 2003;85:185-192.

25. Hurwitz SR, Slawson D, Shaughnessey A. Orthopaedic information mastery: applying evidence-based information tools to improve patient outcomes while saving orthopaedists' time. J Bone Joint Surg Am. 2000;82:888-894.

26. Jakob RP, Franz T, Gautier E, Mainil-Varlet P. Autologous osteochondral grafting in the knee: indication, results, and reflections. Clin Orthop Relat Res. 2002;401:170-184.

27. Jakobsen RB, Engebretsen L, Slauterbeck JR. An analysis of the quality of cartilage repair studies. J Bone Joint Surg Am. 2005;87:2232-2239.

28. Johnson LL. Arthroscopic abrasion arthroplasty historical and pathologic prospective: present status. Arthroscopy. 1986;2:54 69.

29. Knutsen G, Engebretsen L, Ludvigsen TC, Drogset JO, Grøntvedt T, Solheim E, Strand T, Roberts S, Isaksen V, Johansen O. Autologous chondrocyte implantation compared with microfracture in the knee: a randomized trial. J Bone Joint Surg Am. 2004;86:455-464.

30. Lang TA, Secic M. How to Report Statistics in Medicine: Annotated Guidelines for Authors, Editors, Reviewers. Philadelphia, PA: American College of Physicians; 1997.

31. Messner K, Gillquist J. Cartilage repair: a critical review. Acta Orthop Scand. 1996;67:523-529.

32. Micheli LJ, Browne JE, Erggelet C, Fu F, Mandelbaum B, Moseley JB, Zurakowski D. Autologous chondrocyte implantation of the knee: multicenter experience and minimum 3-year follow-up. Clin J Sports Med. 2001;11:223-228.

33. Minas T, Peterson L. Advanced techniques in autologous chondrocyte transplantation. Clin Sports Med. 1999;18:13-44.

34. Noyes FR, Stabler CL. A system for grading articular cartilage lesions at arthroscopy. Am J Sports Med. 1989;17:505-513.

35. Outerbridge RE. The etiology of chondromalacia patellae. J Bone Joint Surg Br. 1961;43:752-757.

36. Peterson L, Brittberg M, Kiviranta I, Akerlund EL, Lindahl A. Autologous chondrocyte transplantation: biomechanics and longterm durability. Am J Sports Med. 2002;30:2-12.

37. Peterson L, Minas T, Brittberg M, Nilsson A, Sjögren-Jansson E, Lindahl A. Two- to 9-year outcome after autologous chondrocyte transplantation of the knee. Clin Orthop Relat Res. 2000;374: 212-234.

38. Pridie KH. A method for resurfacing osteoarthritic knee joints. J Bone Joint Surg Br. 1959;41:618-619.

39. Roberts S, McCall IW, Darby AJ, Menage J, Evans H, Harrison PE, Richardson JB. Autologous chondrocyte implantation for cartilage repair: monitoring its success by magnetic resonance imaging and histology. Arthritis Res Ther. 2003;5:R60-R73.

40. Shelbourne KD, Jari S, Gray T. Outcome of untreated traumatic articular cartilage defects of the knee: a natural history study. J Bone Joint Surg Am. 2003;85(suppl 2):8-16.

41. Spindler KP, Kuhn JE, Dunn W, Matthews CE, Harrell FE Jr, Dittus RS. Reading and reviewing the orthopaedic literature: a systematic, evidence-based medicine approach. J Am Acad Orthop Surg. 2005;13:220-229. 
42. Steadman JR, Rodkey WG, Briggs KK. Microfracture to treat full-thickness chondral defects: surgical technique, rehabilitation, and outcomes. J Knee Surg. 2002;15:170-176.

43. Steadman JR, Rodkey WG, Rodrigo JJ. Microfracture: surgical technique and rehabilitation to treat chondral defects. Clin Orthop Relat Res. 2001;391(suppl):S362-S369.

44. Steadman JR, Rodkey WG, Singleton SB, Briggs KK. Microfracture technique for full-thickness chondral defects: technique and clinical results. Oper Tech Orthop. 1997;7:300-304.

45. Visna P, Pasa L, Cizmar I, Hart R, Hoch J. Treatment of deep cartilage defects of the knee using autologous chondrocyte transplantation and by abrasive techniques:a randomized controlled study. Acta Chir Belg. 2004;104:709-714.

46. Ware JE Jr, Sherbourne CD. The MOS 36-item short form health survey (SF-36). I: conceptual framework and item selection. Med Care. 1992;30:473-483.

47. Wright JR, Swiontkowski MF, Heckman JD. Editorial: introducing levels of evidence to The Journal. J Bone Joint Surg Am. 2003;85:1-3. 